\title{
REPLACEMENT CLUTCHES BY KENTISH PLOVERS ${ }^{1}$
}

\author{
Juan A. Amat, Rosendo M. Fraga ${ }^{2}$ and Gonzalo M. Arroyo 3 \\ Estación Biológica de Doñana, C. S. I. C., Apartado 1056, E-41080 Sevilla, Spain, e-mail: aguilar@cica.es
}

\begin{abstract}
We examined factors affecting renesting rates in a population of Kentish Plovers (Charadrius alexandrinus) in southern Spain over six breeding seasons. We show that renesting was mainly constrained by time, and not by female body condition. Renesting partially compensated for initial clutch losses. The interval from loss of the first clutch to initiation of the replacement clutch was not affected by the number of days of incubation preceding nest loss. Renesting plovers moved considerable distances from first nests. Distances moved between nesting attempts by pairs that had lost chicks were similar to those of pairs that lost eggs. Nest cover did not differ between first and second nests when the first nest was successful, but it was greater in second nests when the first nest was unsuccessful. Yet, nest cover had no influence on the fate of such replacement clutches, probably due to a high diversity of predators at our study site. Females that laid replacement clutches did not delay breeding or breed less frequently in years after they had laid replacement clutches. Even when the success of replacement clutches is moderate, this breeding strategy may be important in accounting for individual lifetime productivity, especially when nest predation is high, as in the studied population.
\end{abstract}

Key words: Charadrius alexandrinus, Kentish Plover, laying date, nesting cover, renesting, replacement clutches.

\section{INTRODUCTION}

Many bird species lay replacement clutches after the previous ones have been lost. Renesting ability is affected by a number of factors, including the body condition of laying females, nest success rates, and duration of the breeding season (Johnson et al. 1992, Arnold 1993, Rooneem and Robertson 1997). Renesting rates should be especially high when laying females are in good body condition, when nest failure rates are high, and when there is enough time within the season to initiate another breeding attempt. Furthermore, these factors may interact. For instance, body condition may affect not only the renesting "decision," but also the interval between nesting attempts, which in turn may be constrained by the time remaining in the breeding season.

Although the benefit of a successful replacement clutch is obvious, the laying of replacement clutches may increase lifetime reproductive success only if this strategy does not inflict severe costs, such as a reduction in future fecundity or survival of breeders, as predicted by

\footnotetext{
${ }^{1}$ Received 19 February 1999. Accepted 8 July 1999.

2 Present address: Asociación Ornitológica del Plata, 25 de Mayo 749, 1002 Buenos Aires, Argentina.

${ }^{3}$ Present address: Departamento de Biología Animal, Facultad de Ciencias del Mar, Universidad de Cádiz, E-11510 Puerto Real, Spain.
}

life history theory (Williams 1966, Lessells 1991).

Kentish Plovers (Charadrius alexandrinus) are small shorebirds (body mass of breeders 42 g; Fraga and Amat 1996) that readily renest when they lose their nests (Rittinghaus 1956), making them an ideal species to study the biology of renesting. In this paper we analyze the effect of the above mentioned factors on renesting rates in a small population of Kentish Plovers over six breeding seasons. Our study population is subject to high levels of clutch failure (Fraga and Amat 1996), so renesting could be an important breeding strategy to compensate for previous clutch losses.

With the aim of documenting whether the laying of replacement clutches has costs on breeders, we tested whether Kentish Plovers laying such clutches (1) skipped breeding more frequently after years in which they laid replacement clutches, and (2) bred comparatively later in a year after having laid replacement clutches the previous year. We did not estimate probabilities of female survival because there were not two clearly defined groups according to laying strategies. In other words, there was not a group of individual females that systematically renested after losing nests, nor another group that did not renest. Over the six study-years there were unsuccessful females that did not renest in a given year, yet they renested in another year, thus 
making it difficult to control for the effect of renesting on survival of this long-lived species.

Previous experience may affect nest-site selection, so that individuals that have lost their nest should change nest-site characteristics, or should move to new sites (Greig-Smith 1982, Marzluff 1988, Marjakangas et al. 1997). During our study, some individuals that were successful (hatched at least one chick) lost their chicks to predators before fledging, and thereafter renested. We predicted that nest-site characteristics between nesting attempts of previously successful individuals should be similar, whereas unsuccessful individuals should attempt to reduce predation risk by renesting in more concealed nests. Also, if birds used the loss of a clutch to "assess" habitat quality, distances moved between nesting attempts might be shorter for previously successful plovers than for unsuccessful ones.

\section{METHODS}

Our study was conducted during 1991-1996 at Fuente de Piedra Lake $\left(37^{\circ} 06^{\prime} \mathrm{N}, 4^{\circ} 45^{\prime} \mathrm{W}\right)$ in southern Spain, an inland saline shallow lake covering $13.5 \mathrm{~km}^{2}$. Kentish Plovers nest along the shores, as well as on some islets and dikes (Fraga and Amat 1996) that were constructed during the last century when the salt was commercially exploited.

Once a nest was found, it was marked, and the degree of cover recorded using four categories: 0 when the nest was completely exposed, and 1-3 when the nest was covered $<25 \%, 25-$ $75 \%$, or $>75 \%$, respectively, when viewed 1.5 $\mathrm{m}$ above it.

Egg masses were recorded to the nearest 0.1 $\mathrm{g}$ with a portable Sartorius balance, and egg length and breadth were measured with vernier calipers to the nearest $0.1 \mathrm{~mm}$. If the laying date of a nest was unknown, we estimated it by an equation based on the rate of daily mass loss of eggs during incubation in relation to egg volume (Fraga and Amat 1996). Laying dates of each year were standardized by expressing them relative to that of the first nest of the corresponding season. Nests were revisited every 3-6 days to determine their outcome, and sites where $90 \%$ of the plovers nested were visited with the same frequency each season to search for new nests. For unsuccessful nests, we assumed that failure occurred midway between the last visit in which the nest was active and the following visit. Distances between first and replacement nests were measured with a tape if $<100 \mathrm{~m}$, by pacing if they were $100-300 \mathrm{~m}$ apart, and from an aerial photograph if $>300 \mathrm{~m}$ apart.

Adults were captured at nests using walk-in traps, and were individually marked with a metal band and a combination of color bands. The body masses of adults were recorded with a Pesola spring balance to the nearest gram, and we used vernier calipers to measure tarsus lengths to the nearest $0.1 \mathrm{~mm}$. As an index of female body condition, we used the residuals of a regression of body masses on tarsus lengths. Given that individuals were caught during different stages of incubation, if there were changes in their body masses throughout their incubation period, such changes could affect the reliability of the body condition index. Nevertheless, a study at Fuente de Piedra indicated that there were no changes in the body masses of individual Kentish Plovers during the first days of incubation throughout the first days of chick rearing (Amat et al., unpubl. data). Furthermore, at our study site there were no significant changes in the body masses of individual females between nesting attempts within nesting seasons (Fraga and Amat 1996, Amat et al., in press). Some females were identified by their color bands when they departed from nests, and were not captured. Because of this, body condition could not be estimated for all females.

Laying dates could not be estimated for all nests, as some of them were found during windy days when it was not possible to accurately record egg masses, and in the following visit the eggs had been preyed upon or had hatched. The fate of some nests could not be determined. For these reasons, sample sizes varied between analyses.

We define renesting interval as the time between loss of a nest (or chicks from a previous nest) and the date of laying of the first egg in a subsequent nest (Grand and Flint 1996). In our study, renesting intervals were 4-75 days. Probably, periods longer than 14 days after failure mean that the plovers attempted to renest at unknown sites in between. For this reason, in most analyses we have excluded replacement nests with renesting intervals longer than 14 days, although inclusion of replacement nests with longer renesting intervals did not alter any of the results. Nevertheless, in estimations of the proportion of pairs renesting, renesting propensity, 


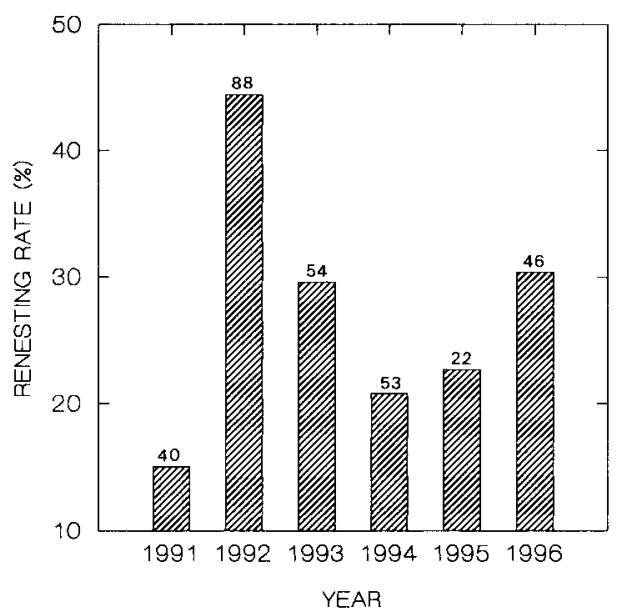

FIGURE 1. Annual variation in renesting rates of Kentish Plovers at Fuente de Piedra Lake. Numbers above the bars are sample sizes (pairs that lost their first clutches).

and nesting success, we have included all first replacement nests.

To assess renesting propensity according to time of season and body condition, we used logistic regressions. For these analyses we considered all females that lost their first clutches, including those that lost chicks from first clutches. For females that renested more than once, we included only first replacement nests. Females that renested after switching mates were excluded, because we will deal with this in another paper. Statistical tests were conducted using SYSTAT (Wilkinson 1990) or STATISTICA (StatSoft 1993). We estimated the power of a statistical test following Cohen (1988). Mean values are presented $\pm \mathrm{SD}$.

\section{RESULTS}

\section{FREQUENCY AND CHARACTERISTICS OF REPLACEMENT CLUTCHES}

The proportion of Kentish Plover females that relaid after having lost their eggs or chicks varied annually between $15-44 \%$ (Fig. 1). The percentages of replacement clutches for lost chicks varied between $0 \%(n=14$ replacement clutches) in 1996 and 45\% $(n=11)$ in 1994. Kentish Plover chick mortality was mainly due to predation by Gull-billed Terns (Sterna nilotica) (Amat et al., in press). Of the females that laid replacement clutches over all 6 years $(n=75)$, $85.3 \%$ laid one replacement clutch, $12.0 \%$ laid two, and $2.7 \%$ laid three. There was no differ- ence in the renesting interval between females that during the season only laid one replacement clutch $(9.3 \pm 2.7$ days, $n=43)$ and those that laid $>1$ replacement clutch $(8.0 \pm 6.1$ days, $n$ $=8 ; t_{49}=1.3, P=0.20$ ). There also was no relationship between the renesting interval and the distance between the first and the second nest $(r=0.1, n=51, P=0.40$ ). Renesting interval was not affected by the number of days of incubation that preceded nest loss $(r=-0.04$, $n=51, P=0.81$ ).

There was no significant difference in the distance between first and second nests between females laying $>1$ replacement clutch (544 \pm $1,058 \mathrm{~m}, n=9)$ and those that only laid a replacement clutch $\left(418 \pm 817 \mathrm{~m}, n=46 ; t_{53}=\right.$ $0.5, P=0.69)$. Distances were also similar whether the first nest was successful $(85 \pm 116$ $\mathrm{m}, n=6)$ or unsuccessful $(482 \pm 892 \mathrm{~m}, n=$ $49 ; t_{53}=1.1, P=0.28$ ), although probably owing to small sample size in one category, the statistical power of the last test was low (power $<0.31$, for $n_{1}=6, n_{2}=49$, at $\alpha=0.05$ ). The degree of nest cover when first nests were successful was similar in first $(2.2 \pm 1.2, n=6)$ and second nests $(2.3 \pm 0.8, n=6$; Wilcoxon matched-pairs test, $z=0.4, P=0.67$ ), but was significantly greater when first nests were unsuccessful (cover of first nests $=1.0 \pm 1.0, n=$ 49; cover of replacement nests $=1.4 \pm 1.1, n$ $=49 ; z=2.3, P=0.02$ ). Despite the greater concealment of the latter replacement clutches, nest cover had no influence on their fate $\left(G_{2}=\right.$ $0.8, P=0.96$ ). Clutch sizes were larger in first (2.9 \pm 0.3 eggs, $n=55$ ) than in replacement nests $\left(2.8 \pm 0.5\right.$ eggs, $n=55$; paired $t_{54}=2.1$, $P=0.04)$.

\section{FACTORS AFFECTING RENESTING}

Based on logistic regression, there was a significant negative relationship between the probability of renesting and the laying date of the previous nest $\left(\chi^{2}{ }_{1}=18.3, P<0.001\right)$. In fact, the mean laying dates of females that laid replacement clutches $(41.0 \pm 22.5, n=55)$ were significantly earlier that those of females that did not relay $\left(58.2 \pm 26.9, n=200 ; t_{253}=4.3, P\right.$ $<0.001$ ). Moreover, the mean first-nest laying date of females that laid $>1$ replacement clutch $(26.8 \pm 19.4, n=9)$ was significantly earlier than that of females that only laid one replacement clutch $\left(43.8 \pm 22.2, n=46 ; t_{53}=2.1, P\right.$ $=0.04$ ). 
The body condition of females did not affect whether they laid a replacement clutch $\left(\chi^{2}{ }_{1}=\right.$ $1.0, P=0.31$ ). There was no difference in the body condition of those females that relaid (condition index $=-0.4 \pm 3.1, n=52$ ) and that of females that did not relay $(0.1 \pm 2.8, n=184$; $t_{234}=1.0, P=0.32$ ). Furthermore, the renesting interval was not affected by the body condition of females in first nests ( $r=0.05, n=48, P=$ 0.74 ), nor was there a relationship between the body condition of females and laying dates $(r=$ $0.1, n=232, P=0.13$ ).

\section{BENEFITS AND COSTS OF RENESTING}

Of second nests $(n=75), 30.7 \%$ were successful, $53.3 \%$ were depredated, $10.7 \%$ were deserted, and the fate of $5.3 \%$ of the nests could not be determined. Of third nests $(n=11), 27.3 \%$ were successful, $45.5 \%$ were depredated, $18.2 \%$ were deserted, and the fate of $9.1 \%$ was not known. Only two females were known to lay four clutches, all of which were depredated.

Of 25 females that in a given year laid replacement clutches, 15 did not skip breeding the following year, and 10 skipped breeding (or were not recorded breeding) the following year. These same 25 females bred in other years in which they did not lay replacement clutches, and 15 of them did not skip breeding the following year, but the remaining 10 females did skip breeding the following year. This indicates that females did not skip breeding more frequently when they had laid replacement clutches than when they did not lay them $\left(G_{1}=0.0\right)$.

For the 15 females that did not skip breeding in years after which they had laid replacement clutches, there was no difference in mean laying dates between first nests in the years in which replacement clutches were laid $(41.9 \pm 21.4)$ and laying date the following year $(55.0 \pm 24.8$; paired $t_{14}=1.6, P=0.13$ ). Thus, by laying replacement clutches in a year, females did not breed significantly later the next year.

\section{DISCUSSION}

Our study suggests that to renest, Kentish Plovers at Fuente de Piedra are mainly constrained by time, with birds that lay early being the most likely to lay replacement clutches. At Fuente de Piedra, a few plovers initiated up to four nesting attempts, but in coastal sites with a longer duration of the breeding season, the plovers may nest up to five times (Warriner et al. 1986). In our study, the body condition of breeding females did not affect the probability of laying replacement clutches.

The extent to which Kentish Plovers renested during our study ( $31 \%$ of pairs based on the loss of initial clutches) is within the range $(15-50 \%)$ reported for shorebirds (Erckmann 1983, Colwell and Oring 1988). Renesting enabled Kentish Plovers to partially compensate for losses of previous nests. Although the success of replacement clutches was moderate, the laying of these clutches may be important in accounting for individual lifetime productivity, especially due to the high nest predation levels to which the studied population is subject (Fraga and Amat 1996), as well as to its apparently low costs, as females did not delay breeding or have reduced breeding opportunities after years in which they had laid replacement clutches.

In shorebirds, the nutrients and energy needed for egg laying are apparently acquired by females immediately before or during the egg laying period (Erckmann 1983). As food availability is high at our study site throughout the nesting season (Amat et al., unpubl. data), no differences should be expected either in the interval between nesting attempts in relation to the number of days of incubation that preceded nest loss, or in clutch sizes between nesting attempts. As expected, renesting intervals for Kentish Plovers at Fuente de Piedra were not affected by the number or days of incubation that preceded nest loss. Renesting intervals were within the range reported for shorebirds, including this same species at other localities (Erckmann 1983, Warriner et al. 1986). Renesting intervals in birds are highly variable (Nesbitt 1988, Massey and Fancher 1989) and probably reflect conditions encountered by females, such as nutrient availability (Swanson et al. 1986), and female characteristics (Rooneem and Robertson 1997, Hegyi and Sasvári 1998). Instead of being affected by female body condition, renesting intervals of Kentish Plovers at Fuente de Piedra are affected by egg size, producing a positive relationship between mean egg volume in second clutches and the interval between the loss of the first nest and onset of laying in second nests (Amat et al., unpubl. data). These findings suggest that although food availability is generally high, resources assigned to egg formation could limit renesting ability.

Contrary to expectations, clutch sizes were 
smaller in replacement than in first nests; this also has been found in some bird species (McAuley et al. 1990, Brown and Morris 1996, Rooneem and Robertson 1997), but not in others (Nesbitt 1988). Arnold (1993) indicated that there were no differences between first and replacement clutches of American Coots (Fulica americana) after controlling for seasonal effects. At Fuente de Piedra, predation rates of Kentish Plover nests increased seasonally, as did partial clutch losses (Fraga and Amat 1996). Thus, replacement clutches could have lost an egg to predators before we found them. In support of this possibility, we found no differences in the clutch sizes of sequentially polyandrous Kentish Plovers in spite of the interval between clutches being much longer for polyandrous birds than for those laying replacement clutches (Amat et al. 1999).

The distances that Kentish Plovers moved to initiate replacement clutches were considerable, as found in this and other shorebird species (McAuley et al. 1990, Székely and Lessells 1993). Contrary to our prediction, we found that distances moved between nesting attempts were similar for previously successful plovers and for unsuccessful ones, although due to small sample size the power of the statistical test was low. As predicted, characteristics of nesting sites of those pairs that hatched the first clutch successfully, but renested after losing the chicks, were similar between nesting attempts. This contrasts with pairs that lost their first clutches, because they renested in more concealed sites. The greater use of more concealed sites by pairs that lost their first clutches was likely not due to changes in habitat preferences as the season advanced (e.g., to protect eggs and incubating birds from the heat of the sun) given that there were no seasonal changes in the use of nesting cover at the population level (Fraga and Amat 1996). Such greater use of more concealed sites likely represents a strategy conditioned on previous experience of renesting birds that had lost their first clutches to predators. The fact that the fate of replacement clutches was not affected by their degree of concealment could be due to a great diversity of predators at Fuente de Piedra (Fraga and Amat 1996), which would preclude the existence of predictably safe nest sites (Colwell 1992, Filliater et al. 1994).

The opportunity to lay replacement clutches may also play an important role in the mating strategies of shorebirds (Erckmann 1983). Incubation is shared by both sexes in the Kentish Plover, and mate-switching is less frequent within than between breeding seasons (Rittinghaus 1956, Warriner et al. 1986, Székely and Lessells 1993). Given that time may be the main constraint on replacement laying, it may not pay individuals to switch mates after clutch failure if mate-switching is a time consuming process.

\section{ACKNOWLEDGMENTS}

Funds for this project were provided by Dirección General de Investigación Científica y Técnica (DGICYT, grants PB92-0115 and PB95-0110) and Junta de Andalucía (Plan Andaluz de Investigación, research group RNM 0105). During field work, RMF held a fellowship from Ministerio de Educación y Ciencia (DGICY'T program "Estancias Temporales de Científicos Extranjeros en España"). The Consejería de Medio Ambiente, Junta de Andalucía, authorized our work at the Reserva Natural Laguna de Fuente de Piedra, where its director, M. Rendón, provided facilities. In addition, A. Arroyo, R. Camarena, J. M. Ramírez, J. Rubio, M. Siquier, and M. Vázquez facilitated our field work. Zoltán Hegyi and an anonymous reviewer provided constructive comments on the manuscript.

\section{LITERATURE CITED}

Amat, J. A., R. M. FraGa, AND G. M. Arroyo. 1999. Brood desertion and polygamous breeding in the Kentish Plover Charadrius alexandrinus. Ibis 141, in press.

ARNOLD, T. W. 1993. Factors affecting renesting in American Coots. Condor 95:273-281.

BRown, K. M., AND R. D. MoRRIs. 1996. From tragedy to triumph: renesting in Ring-billed Gulls. Auk 113:23-31.

COHEN, J. 1988. Statistical power analysis for the behavioral sciences. 2nd ed. Lawrence Erlbaum, Hillsdale, NJ.

Colwell, M. A. 1992. Wilson's Phalarope nest success is not influenced by vegetation concealment. Condor 94:767-772.

Colwell, M. A., AND L. W. ORING. 1988. Breeding biology of Wilson's Phalarope in southcentral Saskatchewan. Wilson Bull. 100:567-582.

ERCKMANN, W. J. 1983. The evolution of polyandry in shorebirds: an evaluation of hypotheses, p. 113168. In S. K. Waser [ED.], Social behavior of female vertebrates. Academic Press, New York.

Filliater, T. S., R. BReItwisch, and P. M. NeAlen. 1994. Predation on Northern Cardinal nests: does choice of nest site matter? Condor 96:761-768.

FraGA, R. M., AND J. A. AMAT. 1996. Breeding biology of a Kentish Plover (Charadrius alexandrinus) population in an inland saline lake. Ardeola 43:69-85.

Grand, J. B., AND P. L. Flint. 1996. Renesting ecology of Northern Pintails on the Yukon-Kuskokwim Delta, Alaska. Condor 98:820-824.

Greig-SMITH, P. W. 1982. Dispersal between nest-sites 
by Stonechats Saxicola torquata in relation to previous breeding success. Ornis Scand. 13:232-238.

Hegy, Z., AND L. Sasvári. 1998. Parental condition and breeding effort in waders. J. Anim. Ecol. 67: 41-53.

Johnson, D. H., J. D. Nichols, AND M. D. Schwartz. 1992. Population dynamics of breeding waterfowl, p. 446-485. In B. D. J. Batt, A. D. Afton, M. G. Anderson, C. D. Ankney, D. H. Johnson, J. A. Kadlec, and G. L. Krapu [EDS.], Ecology and management of breeding waterfowl. Univ. Minnesota Press, Minneapolis, MN.

Lessells, C. M. 1991. The evolution of life histories, p. 32-68. In J. R. Krebs and N. B. Davies [EDS.], Behavioural ecology: an evolutionary approach. 3rd ed. Blackwell Scientific, Oxford.

MarJakangas, A., P. VALKEAJÄRVI, AND L. IJÄs. 1997. Female Black Grouse Tetrao tetrix shift nest site after nest loss. J. Ornithol. 138:111-116.

MarZlufF, J. M. 1988. Do Pinyon Jays alter nest placement based on prior experience? Anim. Behav. 36:1-10.

Massey, B. W., AND J. M. Fancher. 1989. Renesting by California Least Terns. J. Field. Ornithol. 60: 350-357.

MCAuley, D. G., J. R. LONGCORE, AND G. F. SEPIK. 1990. Renesting by American Woodcocks (Scolopax minor) in Maine. Auk 107:407-410.
NeSBitT, S. A. 1988. Nesting, renesting, and manipulating nesting of Florida Sandhill Cranes. J. Wildl. Manage. 52:758-763.

RITTINGHAUS, H. 1956. Untersuchungen am Seeregenpfeifer (Charadrius alexandrinus L.) auf der Insel Oldeoog. J. Ornithol. 97:117-155.

RoONEEM, T. M., AND R. J. RoBERTSON. 1997. The potential to lay replacement clutches by Tree Swallows. Condor 99:228-231.

STATSOFT. 1993. STATISTICA: release 4.5. StatSoft, Inc., Tulsa, OK.

Swanson, G. A., T. L. Shaffer, J. F. Wolf, and F. B. LEE. 1986. Renesting characteristics of captive Mallards on experimental ponds. J. Wildl. Manage. 50:32-38.

SzÉKELY, T., AND C. M. LESSELls. 1993. Mate change by Kentish Plovers Charadrius alexandrinus. Ornis Scand. 24:317-322.

Warriner, J. S., J. C. Warriner, G. W. PAGE, AND L. E. STENZEL. 1986. Mating system and reproductive success of a small population of polygamous Snowy Plovers. Wilson Bull. 98:15-37.

WILKINSON, L. 1990. SYSTAT: the system for statistics. SYSTAT, Inc., Evanston, IL.

WILliams, G. C. 1966. Natural selection, the cost of reproduction, and a refinement of Lack's principle. Am. Nat. 100:687-690. 